ASEAN Journal of Chemical Engineering 2021, Vol. 21, No. 2, $158-169$

\title{
Comparison of Microwave-Assisted Extraction to Soxhlet Extraction of Mango Seed Kernel Oil using Ethanol and n- Hexane as Solvents
}

June Neil G. Balacuit ${ }^{1}$

Jollana Dianne A. Guillermo ${ }^{1}$

Reuben James Q. Buenafe ${ }^{1}$

Allan N. Soriano *,2

${ }^{1}$ School of Chemical, Biological, and Materials Engineering and Sciences, Mapúa University, Intramuros, Manila, Philippines

${ }^{2}$ Chemical Engineering Department, Gokongwei College of Engineering, De La Salle University, 2401 Taft Avenue, Manila, Philippines

*E-mail: allan.soriano@dlsu.edu.ph

Submitted 23 January 2021

Revised 05 October 2021

Accepted 08 October 2021

Abstract. Mango seed kernel oil was extracted by Soxhlet Extraction (SE) and Microwave-Assisted Extraction (MAE) with ethanol and $n$-hexane as extraction solvents. To optimize the extraction condition for $\mathrm{SE}$, the temperature was set to $90^{\circ} \mathrm{C}$ for ethanol and $80^{\circ} \mathrm{C}$ for $\mathrm{n}$-hexane with varying solvent-to-feed ratios (S/F ratio) of 75/12,75/10, and 60/6 mL/g. As for $M A E$, the same $S / F$ ratios were considered. Extraction was done for 5, 10, and 15 minutes with microwave power levels of 120 and $240 \mathrm{~W}$. It was found out that the highest yield per extraction process for SE was: $18.00 \pm 0.25 \%$ and $9.38 \pm 2.03 \%$ using ethanol and n-hexane, respectively; and $6.69 \pm 0.05 \%$ and $4.68 \pm 0.06 \%$ using ethanol and $n$-hexane, respectively for MAE. It was also noted that MAE, with the microwave power level of $120 \mathrm{~W}$ has less extraction time for about 15 minutes as compared to SE of 8 hours. Also, the best S/F ratio in this study is $60 / 6$ for all processes. In oil quality determination, the oil extracted was examined through several tests such as FTIR, GC-MS, acid value, \% FFA, iodine value, saponification value, and melting point. It was noted that oil extracted in ethanol has a better yield compared to that of $n$-hexane but the oil extracted using $n$-hexane would provide superior quality.

Keywords: Acid value, Free-fatty acid, lodine value, Mango seed kernel, Microwave-assisted extraction, Saponification value, Soxhlet extraction

\section{INTRODUCTION}

Mango (Mangifera indica L.) is the third most important fruit crop in the Philippines based on export volume and value next to banana and pineapple. About $70 \%$ of production is consumed locally wherein the predominant cultivars are Pico (Piko), Katchamita (Indian Mango), and Pahutan
(Mangifera altissima) and the country's export variety is the Carabao mango (Manggang kalabaw). Its production is mainly for the consumption of its fleshy pulp but other products were also derived from the pulp including mango puree, mango juice, dried mangoes, concentrates, frozen mangoes, mango glaze, edible parts, mango in brine, and mango preserves (BOI 2011). After the 
consumption or the industrial processing of the fruits, considerable amounts of mango seeds are discarded as waste (45-65\% pulp, $15-20 \%$ peels, $10-15 \%$ pulpier waste, $10-20 \%$ stones) (Puravankara et al. 2000).

Mango seed is made of a firm material enclosing the kernel. Morphologically, the mango fruit is divided into epicarp, mesocarp, and endocarp as shown in Figure 1. The fleshy part of the fruit, the mesocarp is utilized during the processing of juice, pulp, and mango slices for canning. Although the size of the epicarp and endocarp are highly influenced by the varieties, they account for $15-20 \%$ and $20-60 \% \mathrm{w} / \mathrm{w}$ of the whole fruit, respectively, while the kernel accounts for 45$75 \%$ of the endocarp (Ashoush and Gadallah 2011).

Mango kernel contains nearly $15 \mathrm{wt} . \%$ of oils (Kittiphoom and Sutasinee 2015) and can be used for the extraction of edible oils and as a supplement to wheat flour (Kittiphoom 2012). Mango kernel oil was also found to be rich in phenolic compounds according to Soong and Barlow (2006) and is a good alternative natural ingredient or additive in various body and skincare products, including lotions, sun protection creams, moisturizer, and soaps (Casas et al. 2015). In addition, potential antioxidants and high phenolic content of mango kernels can be used to improve the quality and properties of food, such as biscuits based on the study of Ashoush and Gadallah (2011).

Over the past decades, extraction has always been a formidable technique in extracting oils from seeds. Research about extraction provided a foundation for the next generations to work on. Such a technique is employed for the isolation of bioactive compounds and vegetable oils from plant materials (Self, 2005). Extraction of oils from oilseeds can be carried out by mechanical pressing or a solvent. However, solvent extraction or chemical extraction is more efficient (Keneni and Marchetti 2017).

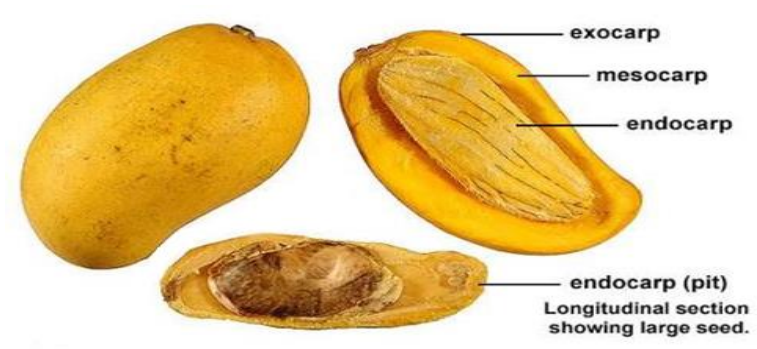

Fig. 1: Cross Section of Mango Fruit (Armstrong 2009).

Solvent extraction is capable of extracting $99 \%$ of oil resulting in a good yield (Augustus et al. 2002). Soxhlet extraction (SE) is the most common method of solvent extraction used because it can extract more sample mass and it is non-matrix dependent. The drawbacks are long extraction times due to slow analyte diffusion and also the desorption from the sample matrix to the extraction fluid is needed as an additional step (Mustafa 2012).

Among the new available methods, microwave pretreatment of seeds is considered to be a simple and desirable technique for the production of high-quality vegetable oil as it allows better retention and availability of desirable nutraceuticals in the extracted oil such that this receives attention over other thermal treatments (Takagi and Yoshida 1999, Uquiche et al. 2008, Destandau et al. 2015). In comparison to conventional methods, microwave pretreatment for oil extraction has many advantages, including, improvement of extracted oil yield and quality, direct extraction capability, lower energy consumption, faster processing time, and reduced solvent levels (Chen et al. 2007, Azadmard-Damirchi et al. 2010). Additionally, the time of exposure to microwave radiation has a significant effect 
160 Comparison of Microwave-Assisted Extraction to Soxhlet Extraction of Mango Seed Kernel Oil using Ethanol and $\mathrm{n}$-Hexane as Solvents

on oil extraction yield (Uquiche et al. 2008) and extraction efficiency (Moreno et al. 2003, Destandau et al. 2015). However, an extensive literature search showed that there are very limited applications of this method on the extraction of oil from the mango seed.

Thus, the main problem of this research is to increase the extraction yield of oil from mango seeds with polar and non-polar solvents incorporating MAE. Specifically, it aims to compare the extraction performance of oil with SE and MAE in terms of yield and quality, to characterize the oil that would be extracted, to study the effect of polar/nonpolar solvents on extraction yield and oil quality, and to study the effect of varying the conditions such as extraction time, extraction temperature, microwave power level, and solvent to feed ratio on extraction yield.

\section{EXPERIMENTAL SECTION}

Figure 2 presented the flow diagram of the applied methods considered in this work. The succeeding sections discussed the details of each method.

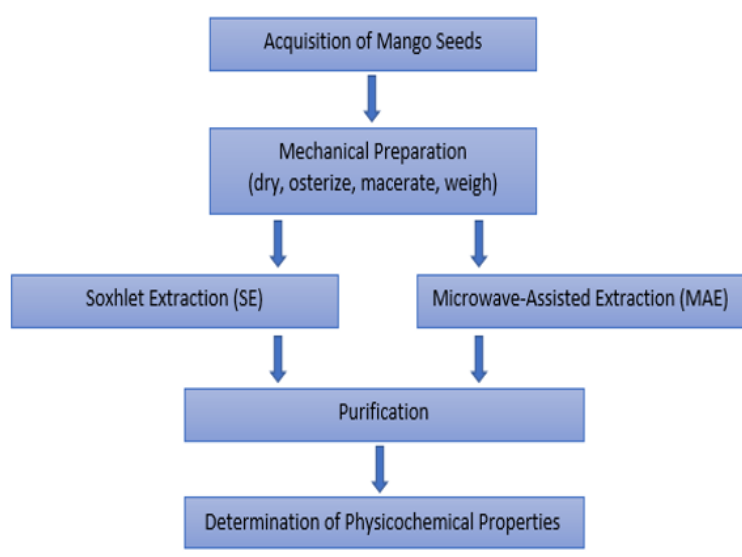

Fig. 2: Flow Diagram of the Applied Methods.

\section{Acquisition of Mango Seeds}

This study focused on a specific type of seed from Indian mango. Seeds were collected from an Indian mango (Mangifera indica L.) from Davao supplier and the sample specimen was brought to the Philippine National Museum for validation of the specific variety.

\section{Mechanical Preparation of Mango Seeds}

Clean seeds collected manually were air-dried. The seeds were de-hulled to remove the shell, and the desired kernel was dried in an oven at $50^{\circ} \mathrm{C}$ for 72 hours until a constant weight to remove excess moisture prior to the extraction process. The sample was then ground using Thomas Wiley Mill and was sieved to a particle size between 150 $\mu \mathrm{m}$ and $845 \mu \mathrm{m}$. The samples were stored in a dry and controlled environment before use.

\section{Soxhlet Extraction (SE)}

The chemicals used were absolute ethanol and $95 \% \mathrm{n}$-hexane for extraction are from Sigma-Aldrich. With different solventto-feed (S/F) ratios, the ground sample weighing $12 \mathrm{~g}, 10 \mathrm{~g}$, and $6 \mathrm{~g}$ was placed into a separate thimble and extracted using 75,75 , and $60 \mathrm{~mL}$ of solvent, respectively, which was placed to a $100-\mathrm{mL}$ round bottom flask, connected to the extractor flask with siphon and condenser. The Soxhlet's extractor apparatus (OSK 8407A) was set to $90^{\circ} \mathrm{C}$ for ethanol and $80^{\circ} \mathrm{C}$ for $\mathrm{n}$-hexane, only $10^{\circ} \mathrm{C}$ higher than the boiling point of the solvent used to avoid thermal degradation on bioactive compounds in the extracts. To find optimum conditions, extraction was done for 4,6 , and 8 hours for ethanol while 2, 4, and 6 hours for $n$-hexane. These operational parameters were based on literature for mango seed oil Soxhlet extraction. The yield was collected by separating the solvent using 
a rotary evaporator (Heidolph Laborota 40001) at an operating temperature of $80^{\circ} \mathrm{C}$ for ethanol and $70^{\circ} \mathrm{C}$ for $\mathrm{n}$-hexane solvent used and the remaining solvent was evaporated off in a fume hood. The rotary evaporator has an aspirator vacuum pump (TRK A-1000S).

\section{Microwave-Assisted Extraction (MAE)}

The solvent was mixed with ground samples and placed in a $250 \mathrm{~mL}$ round bottom flask attached to a condenser. The solvent $(\mathrm{mL})$-to- feed $(\mathrm{g})$ ratio considered was also 75:12 (6.25), 75:10 (7.5), and 60:6 (10). The microwave oven (Hanabishi HMO 20M) extraction times were set for 5,10 , and 15 minutes with varying power of 120 watts and 240 watts. Seeds cake was separated by filtration using Whatman ashless filter paper (grade no.42).

\section{Purification}

The extract was purified using a rotary evaporator (Heidolph Laborota 40001) to remove the solvent at an operating temperature of $80^{\circ} \mathrm{C}$ for ethanol and $70^{\circ} \mathrm{C}$ for n-hexane solvent used. The remaining solvent was evaporated off in a fume hood. These operational parameters were based on past MAE researches. The yield of extraction was expressed as the ratio of the mass of purified oil extract per initial mass of the sample and reported as percentage yield.

\section{Determination of Properties}

The physicochemical properties were then determined. Four samples were subjected to FTIR analysis which was oil extracted from SE and MAE using ethanol and n-hexane as a solvent. The analysis was performed by Thermo Scientific Nicolet 6700 FT-IR apparatus located in the Department of
Chemistry at De La Salle University, Manila. The acid value, iodine value, and saponification value were also identified as prescribed by the methods in the available literature (Niyi 2014).

Two samples were subjected for determination of fatty acid composition which was oil extracted from SE and MAE using ethanol as a solvent. The analysis was performed using Perkin Elmer Clarus 680 Gas Chromatograph and Perkin Elmer Clarus SQ 8T GC/Mass Spectrometer apparatus located in Mach Union Laboratory, Las Piñas City.

\section{RESULTS AND DISCUSSION}

\section{Effect of Operating Parameters on \%Yield}

Tables 1 and 2 show the experimental results for the Soxhlet extraction (SE) and the Microwave-Assisted Extraction (MAE), respectively, using the considered solvents. As presented in these tables, it was found out that as the extraction time, temperature, and power increase, the oil extraction yield also increases.

The effects of the studied parameters on the extraction yield were presented in Figures 3 and 4, respectively for SE and MAE using ethanol as solvent. Using $\mathrm{SE}$, a significant increase in the oil extraction yield was observed in all $S / F$ ratios as the extraction time increases. It was also observed that as the $S / F$ ratio increases from 6.25 to 10 , the extraction yield also increases. Further increase in the $S / F$ ratio to 15 would give a higher extraction yield (Sikdar et al. 2017). However, due to the limitations of the resources, the researchers opted to choose 10 as the optimum S/F ratio. The most appropriate extraction time was found to be at 8 hours, as it resulted in the maximum extraction yield. 


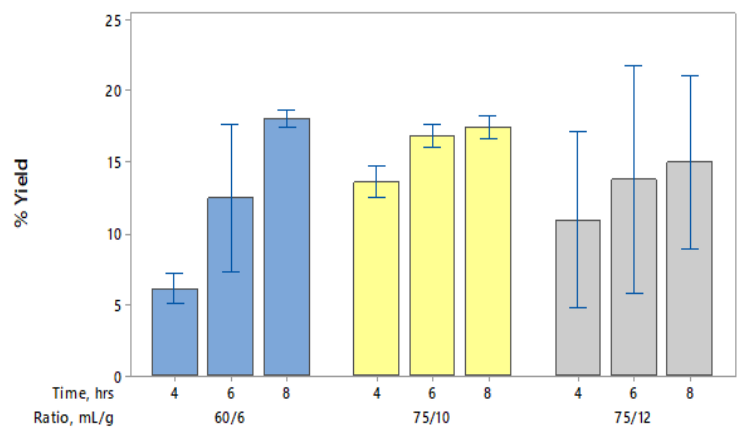

Fig. 3: Plot of \% Yield versus Time and S/F using SE and Ethanol as Solvent.

Using MAE (as shown in Figure 4), it was found that the oil extraction yield increased significantly for all the S/F ratios for the power level of $120 \mathrm{~W}$ when the microwaveassisted times were increased from 0 to 5 minutes, and further increased to 10 and 15 minutes. It was also found out that the $60 / 6$ ratio resulted in a better yield compared to 75/10 and 75/12 S/F ratios. However, such further increase in microwave-assisted times from 5-15 minutes for microwave power of 240 W did not show any significant improvement in oil extraction yield and higher than 5 minutes for the microwave power level of $240 \mathrm{~W}$, as the samples tend to undergo disintegration.

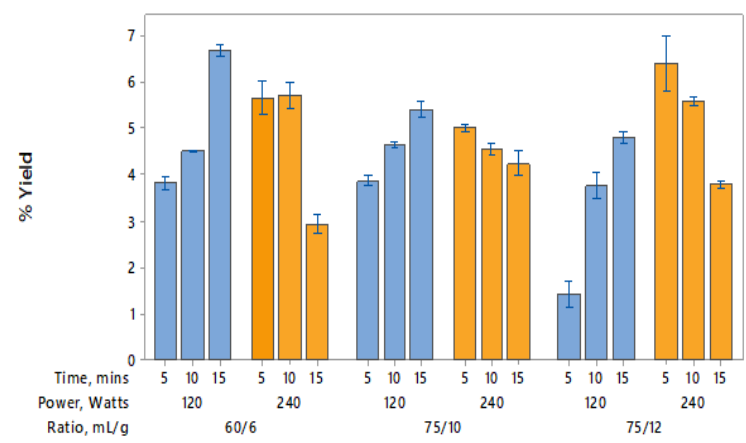

Fig. 4: Plot of \% Yield versus Time, Power, and S/F using MAE and Ethanol as Solvent.

Figures 5 and 6 presented the effects of the studied parameters on the extraction yield, respectively, for SE and MAE using nhexane as solvent. As shown in Figure 5, for $\mathrm{SE}$, there was an increase in oil extraction yield significantly from 2 to 6 hours for all the $\mathrm{S} / \mathrm{F}$ ratios. It was also found out that the $60 / 6$ ratio produced a higher oil yield compared to the $75 / 10$ and 75/12 S/F ratio. Therefore, the longer the extraction time, the higher the oil extraction yield would be for all the S/F ratios, and the most appropriate extraction time was found to be at 6 hours.

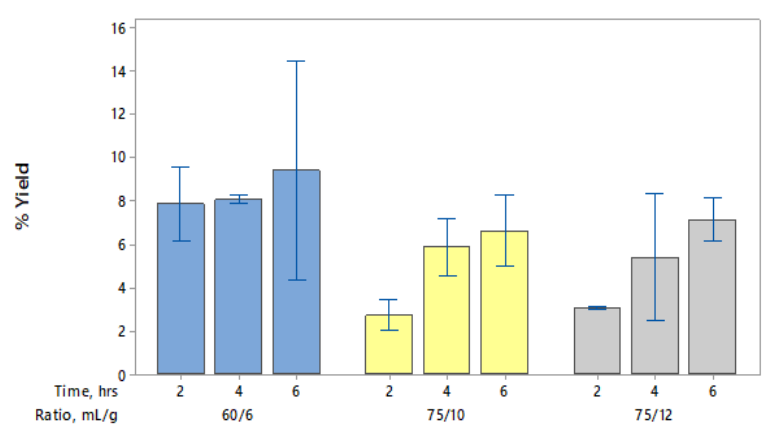

Fig. 5: Plot of \% Yield versus Time and S/F using SE and $\mathrm{n}$-Hexane as Solvent.

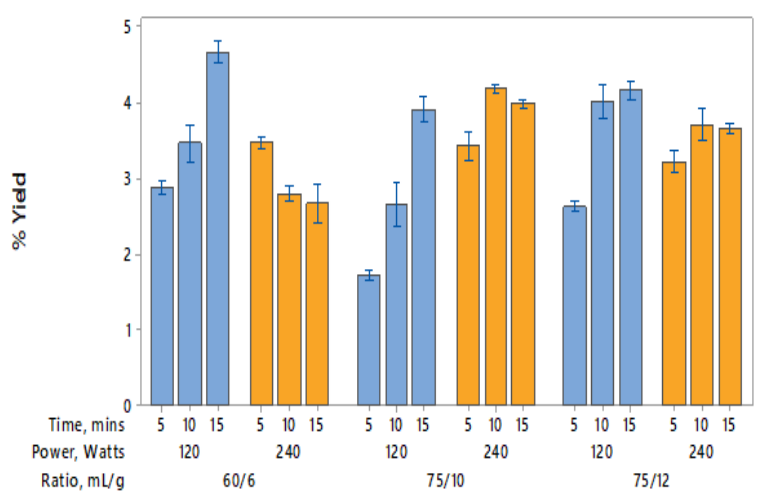

Fig. 6: Plot of \% Yield versus Time, Power, and $S / F$ using MAE and n-Hexane as Solvent.

For MAE as shown in Figure 6, it was found that the effect of using $n$-hexane and ethanol as solvent is similar as the oil extraction yield increased significantly for all the ratios for the power level of $120 \mathrm{~W}$ from 5 to 15 minutes and also 60/6 ratio produced a higher yield among the three. However, there was no further increase in oil extraction yield with the microwave power level of $240 \mathrm{~W}$ for $60 / 6$ ratio as the sample started to disintegrate upon reaching 10 minutes and it was also the 
same for $75 / 10$ and $75 / 12$ ratio as percent recovery of the oil started to decline upon reaching the maximum time for about 15 minutes. This happens because of the combustion of oil vapors from the seeds at this power level which causes the seed to char (Kumar et al. 2018).

The temperature and power are important parameters for extraction techniques and it also contributes to the increase in yield. As for $M A E$, power depends on the solvent's ability to absorb microwaves. In MAE, ethanol as a solvent produces a higher yield compared to that of the $n$-hexane as shown in Table 2 because $n$-hexane is an example of microwave-transparent solvent whereas ethanol is an excellent microwave-absorbing solvent, and solvents that are transparent to microwaves do not heat when submitted. Generally, n-hexane is used for the extraction of volatile oils but the extracted oil from mango seed kernel is not volatile. Therefore, polar solvents like ethanol are better than non-polar like that of $n$-hexane when it comes to higher oil recovery and temperature should be sufficient to ensure a good solubility of compounds and a good penetration of solvent in the plant matrix to enhance extraction yield, but not high enough to degrade the target compounds (Mustafa, 2012).

Table 1. Percentage yield of SE using ethanol and $n$-hexane as solvents

\begin{tabular}{|c|c|c|c|}
\hline $\begin{array}{c}\text { Time } \\
\text { (hours) }\end{array}$ & $75 / 12 \mathrm{~S} / \mathrm{F}^{*}$ & $\begin{array}{l}\text { Ethanol } \\
75 / 10 \mathrm{~S} / \mathrm{F}\end{array}$ & $60 / 6 \mathrm{~S} / \mathrm{F}$ \\
\hline \multicolumn{4}{|c|}{$90^{\circ} \mathrm{C}$ Extraction Temperature } \\
\hline 4 & $10.97 \pm 2.490$ & $13.58 \pm 0.457$ & $6.13 \pm 0.434$ \\
\hline 6 & $13.78 \pm 3.200$ & $16.81 \pm 0.316$ & $12.48 \pm 2.070$ \\
\hline 8 & $15.02 \pm 2.450$ & $17.45 \pm 0.326$ & $18.00 \pm 0.253$ \\
\hline \multirow{2}{*}{$\begin{array}{c}\text { Time } \\
\text { (hours) }\end{array}$} & & n-Hexane & \\
\hline & 75/12 S/F & $75 / 10 \mathrm{~S} / \mathrm{F}$ & $60 / 6 \mathrm{~S} / \mathrm{F}$ \\
\hline \multicolumn{4}{|c|}{$80^{\circ} \mathrm{C}$ Extraction Temperature } \\
\hline 2 & $3.05 \pm 0.029$ & $2.75 \pm 0.278$ & $7.83 \pm 0.675$ \\
\hline 4 & $5.38 \pm 1.170$ & $5.90 \pm 0.533$ & $8.04 \pm 0.077$ \\
\hline 6 & $7.14 \pm 0.398$ & $6.62 \pm 0.644$ & $9.38 \pm 2.030$ \\
\hline
\end{tabular}

${ }^{*} \mathrm{~S} / \mathrm{F}$ is the Solvent-Feed ratio.

Table 2. Percentage yield of MAE using ethanol and n-hexane as solvents

\begin{tabular}{|c|c|c|c|c|c|c|}
\hline \multirow{2}{*}{$\begin{array}{l}\text { Time } \\
\text { (mins) }\end{array}$} & \multirow[b]{2}{*}{$75 / 12$ S/F* } & \multirow{2}{*}{$\begin{array}{c}\text { Ethanol } \\
75 / 10 \mathrm{~S} / \mathrm{F} \\
\end{array}$} & \multirow[b]{2}{*}{$60 / 6 \mathrm{~S} / \mathrm{F}$} & \multirow[b]{2}{*}{$75 / 12 \mathrm{~S} / \mathrm{F}$} & \multirow{2}{*}{$\begin{array}{c}\text { n-Hexane } \\
75 / 10 \mathrm{~S} / \mathrm{F} \\
\end{array}$} & \multirow[b]{2}{*}{$60 / 6 \mathrm{~S} / \mathrm{F}$} \\
\hline & & & & & & \\
\hline \multicolumn{7}{|c|}{120 W Power } \\
\hline 5 & $1.43 \pm 0.109$ & $3.87 \pm 0.041$ & $3.82 \pm 0.061$ & $2.63 \pm 0.025$ & $1.73 \pm 0.026$ & $2.89 \pm 0.034$ \\
\hline 10 & $3.76 \pm 0.109$ & $4.65 \pm 0.030$ & $4.51 \pm 0.011$ & $4.02 \pm 0.083$ & $2.66 \pm 0.119$ & $3.47 \pm 0.102$ \\
\hline 15 & $4.81 \pm 0.050$ & $5.42 \pm 0.069$ & $6.69 \pm 0.048$ & $4.16 \pm 0.047$ & $3.92 \pm 0.064$ & $4.68 \pm 0.058$ \\
\hline \multicolumn{7}{|c|}{240 W Power } \\
\hline 5 & $6.42 \pm 0.239$ & $5.02 \pm 0.032$ & $5.66 \pm 0.144$ & $3.23 \pm 0.058$ & $3.44 \pm 0.081$ & $3.47 \pm 0.031$ \\
\hline 10 & $5.59 \pm 0.040$ & $4.56 \pm 0.049$ & $5.71 \pm 0.084$ & $3.72 \pm 0.089$ & $4.19 \pm 0.021$ & $2.80 \pm 0.046$ \\
\hline 15 & $3.78 \pm 0.034$ & $4.25 \pm 0.106$ & $2.96 \pm 0.084$ & $3.67 \pm 0.030$ & $4.00 \pm 0.023$ & $2.67 \pm 0.105$ \\
\hline
\end{tabular}

* $\mathrm{S} / \mathrm{F}$ is the Solvent-Feed ratio 
164 Comparison of Microwave-Assisted Extraction to Soxhlet Extraction of Mango Seed Kernel Oil using Ethanol and $\mathrm{n}$-Hexane as Solvents

\section{Thermophysical Characterization of the 2015). Extracted Oil}

\section{FTIR Analysis}

The resulting oils from the highest yields (based on SE/MAE and ethanol/nhexane as solvents) are considered for this analysis. Figure 7 shows the obtained FTIR results. As shown in this figure, the graph of the sample from SE and MAE using ethanol matches almost the same since the oil for both extraction processes were extracted using the same solvent so it is expected for the oil to have the same composition and the same went to the sample from SE and MAE using $n$-Hexane where the graphs were also observed to be almost similar. The entire functional groups were shown in Table 3. There were significant changes in the functional groups between SE and MAE. In Table 3, there were new bonds formed for ethanol used as solvent after using MAE which was the alcohol and aldehyde group. While for n-hexane used as the solvent, an alcohol group was formed after using MAE. The effect was caused by the heating process which took place during extraction involving direct heating that was selective towards the sample. This reaction could have caused the disruption of the alkanes bond in the sample which helped the penetration of solvent into the sample as well as the discretion of oil (Norfaezah et al. 2015). Based on the FTIR comparison, it could be deduced that MAE is more advantageous compared to that of using SE because MAE retained the present chemical compound after extraction and enhanced the number of chemical compounds in the sample while for SE the bonds were disrupted (Norfaezah et al.

\section{Acid Value}

It is a measure of hydrolysis of triglycerides into free fatty acids, which affects the quality of lipids. It can be used as a purity examination of oil and shows that oil may have already started decomposition reactions (Kittiphoom and Sutasinee 2015). As presented in Table 4, the acid value in ethanol extract is relatively higher compared to hexane extract. This may indicate that such reactions occur by the action of the lipase enzyme which might come from where the oil was extracted (Vitz et al. 2017). However, the acid value was higher in MAE compared to SE, with ethanol as solvent, due to high temperature that affected hydrolysis. Free fatty acids are not present in purified oil, but noticeable amounts of free fatty acids may be present in crude oils. This is due to the fact that free fatty acids are needed to be removed when purifying since it is prone to oxidation which makes the oil rancid (Mahesar et al. 2014).

\section{Saponification Value (SV)}

It is a measure of the alkali-reactive groups in fats and oils or the degree of saturation of lipids. It can be used to characterize the types of glycerides in the samples. Glycerides containing long-chain fatty acids have lower SVs than those with shorter chain fatty acids (Kittiphoom and Sutasinee 2015). As presented in Table 4, saponification value is relatively lower in ethanol extract compared to hexane extract, which indicates that it contains a very high content of low molecular weight triacylglycerol. However, oil in ethanol 
extract with SE has relatively higher SV than with MAE which may be indicated that MAE extracts more saturated lipids. This is because saturated lipids have high molecular weights and SV is inversely proportional to the molecular weight as shown in Eq. (1).

$$
\mathrm{SV}=3000(56.1 / \text { Molecular Weight })
$$

\section{lodine Value}

It gives a measure of the average degree of unsaturation of lipid or the number of $\mathrm{C}=\mathrm{C}$ double bonds. The iodine value of the analyzed mango seed kernel oil was $11.19 \mathrm{~g} / 100 \mathrm{~g}$ oil and $4.61 \mathrm{~g} / 100 \mathrm{~g}$ oil for SE and MAE, respectively. Decreasing iodine value may be attributed to unsaturation due to oxidation, polymerization, or breakage of the longchain fatty along the process (Kittiphoom and Sutasinee 2015). However, oil in hexane extract had a relatively smaller IV than with ethanol extract which reflected its characteristics such as higher resistance to oxidation, longer shelf life, and higher quality (Kittiphoom and Sutasinee 2013). Thus, iodine values vary due to different fatty acid compositions.

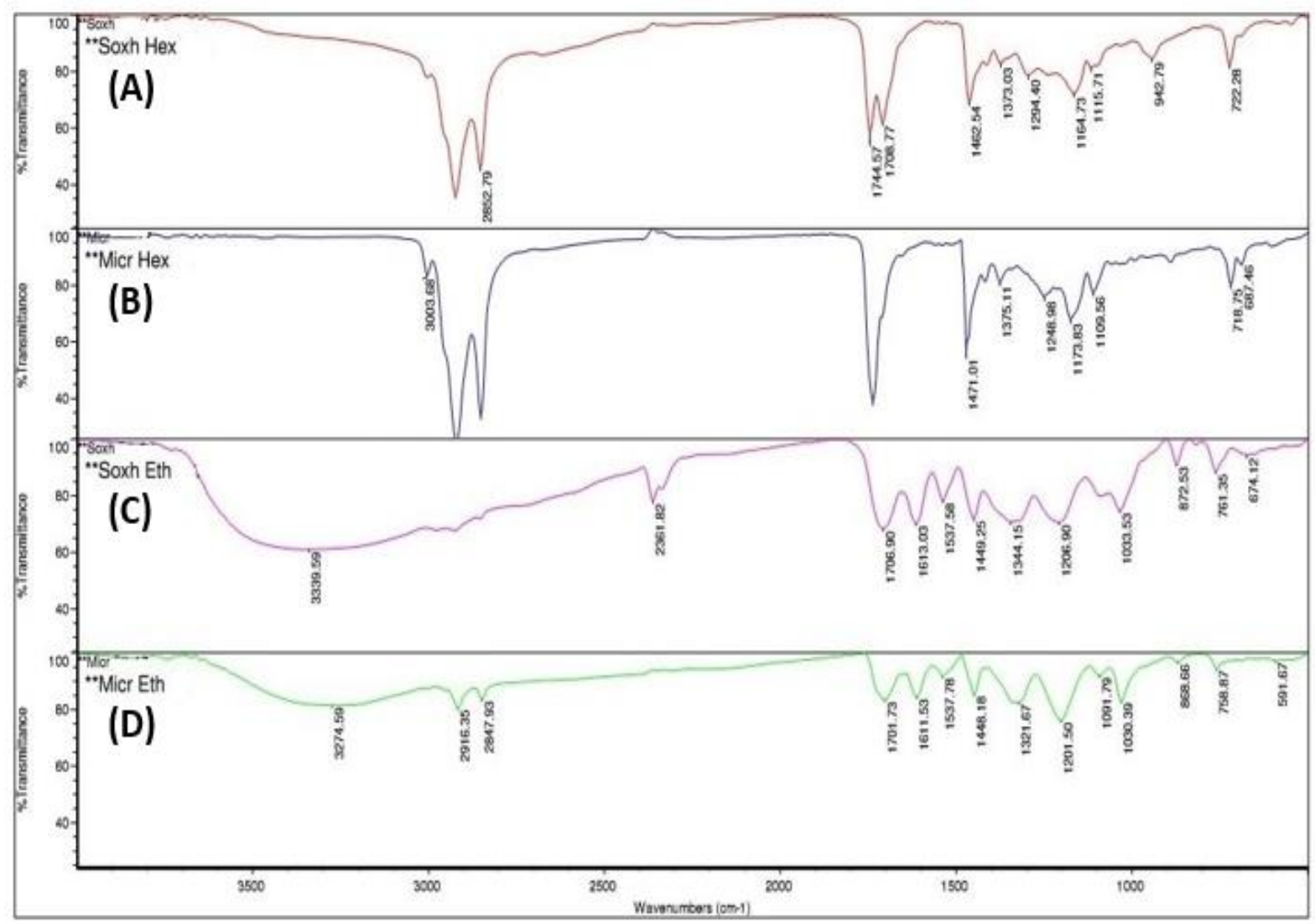

Fig. 7: Comparisons of FTIR Results of Extracted Oils: (A) SE with n-Hexane, (B) MAE with nHexane, (C) SE with Ethanol, and (D) MAE with Ethanol. 
166 Comparison of Microwave-Assisted Extraction to Soxhlet Extraction of Mango Seed Kernel Oil using Ethanol and $\mathrm{n}$-Hexane as Solvents

Table 3. Comparisons of functional groups of extracted oil from mango seed kernel

\begin{tabular}{ccccccc}
\hline $\begin{array}{c}\text { Wave } \\
\text { number } \\
\text { range }\end{array}$ & Group & Compound & $\begin{array}{c}\text { Osing from SE } \\
\text { Ethanol }\end{array}$ & $\begin{array}{c}\text { Oil from MAE } \\
\text { n-Hexane }\end{array}$ & $\begin{array}{c}\text { using } \\
\text { Ethanol }\end{array}$ & $\begin{array}{c}\text { using } \\
\text { n-Hexane }\end{array}$ \\
\hline $3600-3200$ & O-H & Alcohol & $\checkmark$ & & $\checkmark$ & $\checkmark$ \\
$3000-2850$ & C-H & $\begin{array}{c}\text { Alkanes } \\
\text { Aldehyde }\end{array}$ & & $\checkmark$ & $\checkmark$ & $\checkmark$ \\
$3000-1000$ & C=O & Esters & $\checkmark$ & $\checkmark$ & $\checkmark$ & \\
$1680-2000$ & C=C & Alkene & $\checkmark$ & $\checkmark$ & $\checkmark$ & $\checkmark$ \\
$960-600$ & C=C & Aromatics & $\checkmark$ & $\checkmark$ & $\checkmark$ & $\checkmark$ \\
\hline
\end{tabular}

Table 4. Physicochemical properties of mango seed kernel oils (mean \pm S.D.)

\begin{tabular}{lccc}
\hline Physicochemical Property & $\begin{array}{c}\text { Soxhlet } \\
\text { Ethanol } \\
\text { Extract }\end{array}$ & $\begin{array}{c}\text { Microwave } \\
\text { Ethanol } \\
\text { Extract }\end{array}$ & $\begin{array}{c}\text { Microwave } \\
\text { Hexane } \\
\text { Extract }\end{array}$ \\
\hline Acid Value $(\mathrm{mg} \mathrm{KOH} / \mathrm{g}$ oil) & $36.870 \pm 1.02$ & $64.34 \pm 1.74$ & $8.69 \pm 1.94$ \\
Free Fatty Acid $(\%)$ & $18.546 \pm 0.52$ & $32.364 \pm 0.88$ & $4.37 \pm 0.98$ \\
Saponification Value $(\mathrm{mg} \mathrm{KOH} / \mathrm{g}$ oil) & $223.99 \pm 9.39$ & $189.14 \pm 4.78$ & $247.63 \pm 2.27$ \\
lodine Value $(\mathrm{g} / 100 \mathrm{~g}$ oil) & $11.19 \pm 1.51$ & $4.61 \pm 0.33$ & $2.12 \pm 1.17$ \\
Melting Point $\left({ }^{\circ} \mathrm{C}\right)$ & $88.92 \pm 0.965$ & $98.5 \pm 1.3$ & $55.3 \pm 6.02$ \\
\hline
\end{tabular}

\section{Melting Point}

The melting point of oil extracts was found relatively close to the boiling point of the solvent from where it was extracted. This may be due to the impurity of the sample. However, with the decrease of iodine value, there was an increase in the melting point of oil extract with SE vs. MAE. This proved that the degree of unsaturation in the oil increased with MAE.

\section{Fatty Acid Composition}

In this work, the fatty acid compositions of mango seed kernel oil were also evaluated to determine the oil quality (but based only on ethanol) and results are presented in Table 5. It was noted that mango seed kernel oil contained a number of fatty acids which included C2 to C18 saturated and monounsaturated, and other fatty acids. major fatty acid components were oleic, palmitic, and stearic acid. It was noted that unsaturated oleic acids were relatively higher compared to saturated palmitic and stearic acids, which was much desired. These unsaturated fatty acids were very significant in determining the oil stability because of chemical reactions occurring in double bonds. The rates of those oxidation reactions depend on the number of double bonds in the carbon chain. Higher amounts of oleic acid corresponded to a more stable oil quality (Kittiphoom and Sutasinee 2013). The results then suggested that MAE affected the fatty acid compositions of mango seed kernel oil. Thus, the best method to produce extraction yield was MAE. However, extracted oil had few essential fatty acids and traces of other compounds. This may be due to small-scale extraction, which made it a little difficult to ensure purity. 
Table 5. Fatty acid compositions (\%w/w) of mango seed kernel oil

\begin{tabular}{lcc}
\hline Fatty acid & $\begin{array}{c}\text { Soxhlet Ethanol } \\
\text { Extract }\end{array}$ & $\begin{array}{c}\text { Microwave Ethanol } \\
\text { Extract }\end{array}$ \\
\hline Oxalic acid, C2:0 & 2.75 & - \\
Propanoic acid, C3:0 & 4.42 & 14.41 \\
Succinic acid, C4:0 & 0.55 & 1.39 \\
Butanoic acid, C4:0 & - & 1.9 \\
Acetic acid, C4:0 & - & 1.23 \\
Ketoglutaric acid, C5:0 & - & 1.19 \\
Adipic acid, C6:0 & 1.76 & - \\
Palmitic acid, C16:0 & 3.20 & 4.14 \\
Steric acid, C18:0 & 1.41 & 1.52 \\
Oleic acid, C18:1 & 5.14 & 6.58 \\
Glutamic acid, C5:0, amino & - & 0.43 \\
Bicyclo-carboxylic acid, C9:0, cyclo & 1.35 & 0.51 \\
\hline
\end{tabular}

\section{CONCLUSION}

In this present work, mango seed kernel oils were extracted using soxhlet extraction (SE) and microwave-assisted extraction (MAE) with ethanol and $n$-hexane as solvents. The effect of varied parameters, such as time, power or temperature, and solvent-to-feed ratio on extraction yield and oil quality was investigated. The conclusion reached that $M A E$, with a microwave power level of 120 watts, had successful oil yield with less extraction time, about 15 minutes, compared to SE of 8 hours, which was applicable for both ethanol and $n$-hexane solvents. Thus, the major advantage of MAE was the reduced time of extraction and energy consumption costs when compared to conventional methods.

Moreover, it was concluded that the use of polar extraction solvents like ethanol gave a higher extraction yield due to its better microwave absorbing ability. However, according to the analysis of physicochemical properties, results showed oil extracted from $\mathrm{n}$-hexane had better quality because it has lower acid value and free-fatty acid content which makes it more stable. In this research, it was concluded that as extraction time increases, extraction yield also increased, which is applied both to MAE and SE. On the effect of temperature or power, it was noted that a higher microwave power level of $240 \mathrm{~W}$ resulted only in the degradation of the sample. The same with temperature, it should be sufficient to ensure a good solubility of compounds and a good penetration of solvent in the plant matrix to enhance extraction yield, but not high enough to degrade the target compounds. Solvent to feed ratio was also an important parameter in this study. It was noted that a higher $S / F$ ratio increased the extraction recovery. Thus, the best S/F ratio then was $60 / 6$. However, too much of the extracting solvent means more energy and time was required to condense the extraction solution in the later step and purification process. 
168 Comparison of Microwave-Assisted Extraction to Soxhlet Extraction of Mango Seed Kernel Oil using Ethanol and $\mathrm{n}$-Hexane as Solvents

\section{NOMENCLATURE}

$A V$ : acid value $[\mathrm{mg} / \mathrm{g}]$

$B_{1}$ : volume [mL] of $\mathrm{Na}_{2} \mathrm{~S}_{2} \mathrm{O}_{3}$ for blank as in Eqn. (2)

$B_{s} \quad$ : volume $[\mathrm{mL}]$ of $\mathrm{HCl}$ for blank as in Eq. (3)

IV : iodine value

$N \quad:$ normality $[\mathrm{eq} / \mathrm{L}]$

$S_{1}$ : volume $[\mathrm{mL}]$ of $\mathrm{Na}_{2} \mathrm{~S}_{2} \mathrm{O}_{3}$ for sample as in Eq. (2)

Ss : volume [mL] of $\mathrm{HCl}$ for sample as in Eq. (3)

SV : saponification value

\section{REFERENCES}

1. Armstrong, W. P. (2009). "Fruits Called Nuts", https://www2.palomar.edu/users/war mstrong/ecoph8.htm.

2. Ashoush, I. S. and Gadallah, M. G. E. (2011). "Utilization of mango peels and seed kernels powders as sources of phytochemicals in biscuit," World J. Dairy Food Sci., 6, 35-42.

3. Augustus, G., Jayabalan M., and Seiler, G.J. (2002). "Evaluation and bioinduction of energy components of Jatropha curcas," Biomass Bioenergy, 23, 161-164.

4. Azadmard-Damirchi, S., Habibi-Nodeh, F., Hesari, J., Nemati, M., and, Fathi Achachlouei B. (2010). "Effect of pretreatment with microwaves on oxidative stability and nutraceuticals content of oil from rapeseed," Food Chem., 121, 1211-1215.

5. Board of Investments (BOI) (2011). Market opportunity, 6276.

6. Casas, E. V., Comedia, V. J. G., Gilbuena, A. G., and Yaptenco, K. F. (2015). "Optimizing microwave-assisted crude butter extraction from carabao mango
(Mangifera indica) kernels, Sci. Diliman, 27, 41-75.

7. Chen, Y., Xie, M. Y., Gong, X. F. (2007). "Microwave-assisted extraction used for the isolation of total triterpenoid saponins from Ganoderma atrum," J. Food Eng., 81, 162-170.

8. Destandau, E., Michel, T., Elfakir, C. (2015). "Natural Product Extraction: Principles and Applications. Chapter 4 Microwave-assisted extraction," RSC Publishing, 113-156.

9. Keneni, Y. G. and Marchetti, J. M. (2017). "Oil extraction from plant seeds for biodiesel production," AIMS Energy, 5, 316-340.

10. Kittiphoom S. (2012). "Utilization of mango seed," Int. Food Res. J., 19, 1325-1335.

11. Kittiphoom, S. and Sutasinee S. (2013). "Mango seed kernel oil and its physicochemical properties," Int. Food Res. J., 20, 1145-1149.

12. Kittiphoom, S. and Sutasinee S. (2015). "Effect of microwaves pretreatments on extraction yield and quality of mango seed kernel oil," Int. Food Res. J., 22, 960-964.

13. Kumar, R. C., Benal, M.M., Prasad, B. D., Krupashankara, M.S., Kulkarni, R.S., and Siddaligaswamy, N.H. (2018). "Microwave-assisted extraction of oil from pongamia pinnata seeds." Materials Today: Proceedings, 5, 29602964.

14. Larrauri, J. A., Rupérez, P., Borroto, B., and Saura-Calixto, F. (1996). "Mango peels as a new tropical fibre: Preparation and characterization," LWT - Food Sci. Technol., 29, 729-733.

15. Mahesar, S. A., Sherazi, S. T. H., 
Khaskheli, A.R., Kandhro, A.A., and Uddin, S. (2014). "Analytical approaches for the assessment of free fatty acids in oils and fats," Anal. Methods, 6(14), 4956-.

16. Moreno, A. O., Dorantes, L., Galindez, J., and Guzman, R. I. (2003). "Effect of Different Extraction Methods on Fatty Acids, Volatile Compounds, and Physical and Chemical Properties of Avocado (Persea americana Mill.) Oil," J. Agri. Food Chem., 51, 2216-2221.

17. Mustafa, N. B. (2012). "Study on the effect of processing parameters on the extraction of stevioside using soxhlet extractor," Undergraduate Thesis, Universiti Malaysia Pahang.

18. Niyi, O. (2014). "Chemical and Amino Acid Composition of Raw and Defatted African Mango (Irvingia gabonensis) Kernel," Brit. Biotechnol. J., 4, 244-253.

19. Norfaezah, A., Zainab, H., and Othman, H. (2015). "Comparative study between microwave assisted extraction and soxhlet extraction techniques for biooil extracyion from jatropha curcas," J.

Eng. Sci. Technol., Special Issue on SOMCHE 2014 \& RSCE 2014 Conference, 9-16.

20. Puravankara, D., Bohgra V., and Sharma, R.S.. (2000). "Effect of antioxidant principles isolated from mango (Mangifera indica L.) seed kernels on oxidative stability of buffalo ghee (butter-fat)," J. Sci. Food Agric., 80, 522-526.

21. Sikdar, D.C, Hegde, S., Swamynathan,
V., Varsha, S., and Rakesh R. (2017). "Solvent extraction of mango (Mangifera indica L.) seed kernel oil and its characterization," Inter. J. Tech. Res. App., 5, 43-47.

22. Soong, Y. Y. and Barlow P. J. (2006). "Quantification of gallic acid and ellagic acid from longan (Dimocarpus longan Lour.) seed and mango (Mangifera indica L.) kernel and their effects on antioxidant activity," Food Chem., 97, 524-530.

23. Takagi, S., and Yoshida H. (1999). "Microwave heating influences on fatty acid distribution of triacylglycerols and phospholipids in hypocotyls of soybeans (glycine max L.)," Food Chem., 66, 345-351.

24. Uquiche, E., Jeréz, M., and Ortíz, J. (2008). "Effect of pretreatment with microwaves on mechanical extraction yield and quality of vegetable oil from Chilean hazelnuts (Gevuina avellana Mol)," Innov. Food Sci. Emerg. Technol., 9, 495-500.

25. Vitz, E, Moore, J. W., Shorb, J., Resina, X., Wendorff, T., and Hahn A. (2017). Foods: Acid Value and the Quality of Fats and Oils - Chemistry LibreTexts, Chem. Educ. Digit. Libr. https://chem.libretexts.org/Textbook_ Maps/General_Chemistry_Textbook_M aps/Map\%3A_ChemPRIME_(Moore_et _al.)/14lonic_Equilibria_in_Aqueous_So lutions/14.09\%3A_Titration_Curves/Fo ods\%3A_Acid_Value_and_the_Quality_ of_Fats_and_Oils. 